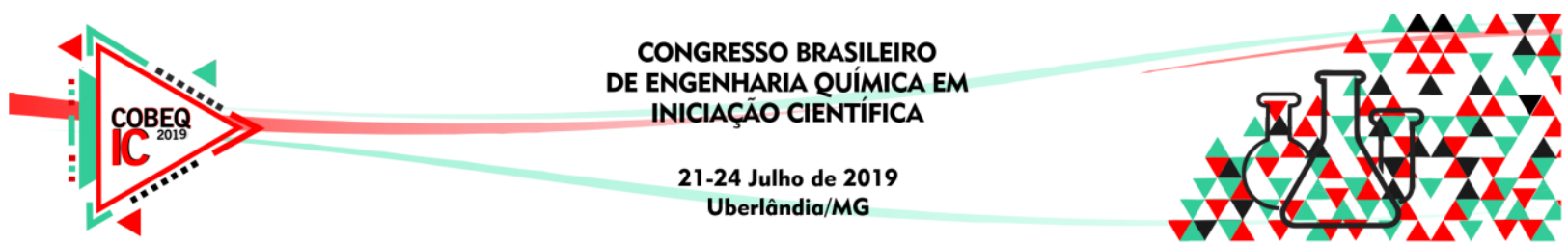

\title{
OBTENÇÃO DE AÇÚCARES FERMENTESCÍVEIS POR MEIO DA HIDRÓLISE ÁCIDA DA VAGEM DO FEIJÃO
}

\author{
K. E. EGÍDIO ${ }^{1}$, B. E. CARLOS ${ }^{2}$, S. K. S. CARMO ${ }^{3}$, R. P. F. MELO ${ }^{4}$ e M. N. de MORAIS ${ }^{5}$ \\ 1,2 Universidade Federal Rural do Semi-Árido, discente do curso Interdisciplinar em Ciência e \\ Tecnologia \\ ${ }^{3,4}$ Universidade Federal Rural do Semi-Árido, Docente do Departamento de Ciências Exatas \\ e Naturais \\ ${ }^{5}$ Universidade Federal Rural do Semi-Árido, Técnico do Departamento de Ciências Exatas e \\ Naturais \\ E-mail para contato: karina.e.e45@gmail.com
}

\begin{abstract}
RESUMO - A descoberta do petróleo, bem como de seus derivados, causa um enorme avanço no mundo pela sua diversidade de aplicação. No entanto, a crise pela sua possível escassez, afeta a população, desencadeando entre os cientistas e diversos profissionais a busca por novas fontes energéticas, visando proporcionar uma minimização da poluição ambiental causada com a sua combustão. Considerando o Bioetanol como uma solução para essa problemática, é válido ressaltar a importância dos materiais lignocelulósicos (palhas, grãos, frutas), como fonte de compostos passíveis a transformação em açúcares fermentescíveis e, consequentemente, produtores de álcool etílico. Por conseguinte, analisando a grande produção agrícola do Brasil, em especial à região do semiárido potiguar, e objetivando a diminuição no índice de desperdício desses produtos, após o descarte, a vagem do feijão surge como fonte de matéria-prima para esse estudo. A pesquisa teve como intuito a realização de um pré-tratamento e hidrólise ácida sobre a matéria-prima, através da análise de quatro variáveis (tipo de ácido, concentração, temperatura e tempo), os quais são processos fundamentais para a obtenção de açúcares fermentescíveis, ponto de interesse desse estudo. Como resultados principais, pôde observar um aumento na concentração de açúcares, para o primeiro processo (pré-tratamento) de aproximadamente 18 vezes, enquanto que para o segundo (hidrólise) de aproximadamente 33 vezes em relação a amostra inicial.
\end{abstract}

\section{INTRODUÇÃO}

Os materiais lignocelulósicos são os compostos orgânicos mais abundantes da biosfera, correspondendo, aproximadamente, a 50\% da biomassa no mundo. Devido as atividades de agricultura e outras práticas são acumuladas, a cada ano, grandes quantidades de resíduos desses materiais. A estrutura desses materiais compõem-se basicamente de um arranjo entre celulose, hemicelulose e lignina. A celulose é a mais abundante nos materiais, subdividida em duas regiões cristalizada e amorfa. A primeira com resistência a formação de açúcares e a segunda mais flexível; a hemicelulose, segunda maior composição, é totalmente passível para formação de açúcares, e a terceira, sendo a lignina, parte menor e mais resistente do material (RODRIGUES et al, 2016). 


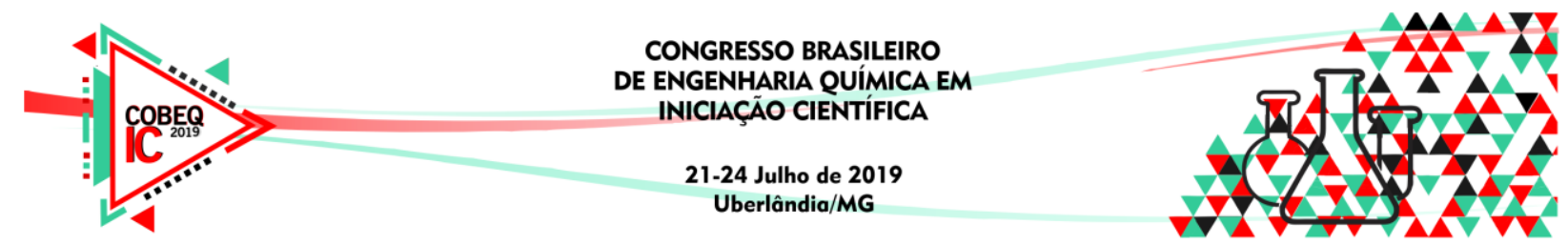

A composição desses materiais possibilita uma formação de açúcares que, consecutivamente, implica numa fermentação e formação de etanol de segunda geração. $O$ álcool é uma fonte energética inovadora, possuindo combustão limpa e renovável (SILVA, 2010).

Por conseguinte, sabendo da crise que o petróleo vem enfrentando pela sua possível escassez e grande poluição ambiental, e além disso, como bem observado, pela elevação dos preços cobrados nos barris que afeta diretamente o consumidor, surge a necessidade de uma fonte alternativa que o substitua. A influência do Brasil na quantidade de produtos agrícolas e juntamente a isso, grande produção e formação de resíduos, esses materiais assumem essa função de alternativa para as próximas fontes energéticas. Logo, visando a região potiguar e seu destaque na produção de feijão, bem como o desperdício de suas vagens, estuda-se esse produto para uma possível formação de açúcares que serão fermentados e destinados a obtenção de etanol, evitando o acúmulo de resíduo no ambiente e produzindo uma energia mais limpa e barata.

\section{FUNDAMENTAÇÃO TEÓRICA}

\subsection{Vagem do feijão}

O feijão, de forma geral, está presente em todo o Brasil, especialmente pela alimentação, possui grande grau de satisfação nas cozinhas brasileiras e de todo o mundo. Originário da espécie Phaseullus Vulgari L, é domesticado desde muito tempo, com três safras durante o ano, liderado pelo Estado do Paraná (IBGE, 2017).

No Rio Grande do Norte (RN), o feijão plantado com predominância é do tipo Vigna, Macassar e Caupi, além de sua grande aceitação em todos os níveis sociais e econômicos, a EMBRAPA afirma ser uma grande fonte alimentícia e de renda para esse Estado (CHAGAS, LIMA, HOLANDA, 2010). O feijão e sua vagem são materiais lignocelulósicos que possuem uma composição básica aplicável a diversas situações, dentre elas, inclusive, como fonte para a formação de açúcares fermentescíveis utilizados na produção de bioetanol.

Essa composição é dividida em celulose, subdividida em duas regiões (amorfa e cristalina), as quais são flexíveis a formação desses açúcares; hemicelulose, composta por cadeias de açúcares, é essencial na formação de açúcares na hidrólise ácida e; lignina parede celular que imprime rigidez a matéria (SILVA, 2010).

Como já visto, o grão possui grande produção e fins satisfatórios, no entanto, forma-se uma grande quantidade de resíduos, que em sua grande maioria, não possuem destino. Um estudo e pesquisa sobre essas propriedades lignocelulósicas da vagem do feijão, encontrou-se uma subdivisão de $41 \%$ em celulose, $20,6 \%$ de hemicelulose e 5,3\% de lignina (CALIXTO, 2016).

\subsection{Hidrólise ácida}

A hidrólise é dada para qualquer reação química que envolva a quebra de uma molécula e, para tal, faz-se o seu uso como forma de obtenção de açúcares fermentescíveis, podendo ser através de métodos envolvendo ácidos, soluções alcalinas ou enzimas. 


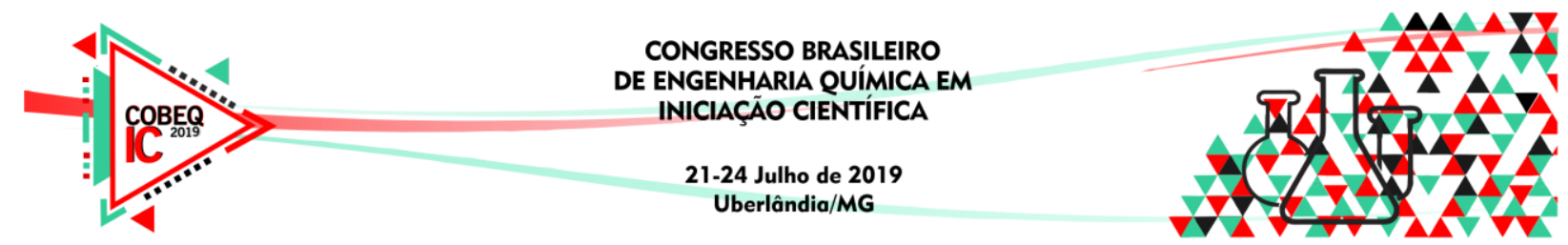

É evidente que os açúcares são provenientes da celulose e hemicelulose, e para a obtenção destes se aplica uma das soluções citadas juntamente com uma temperatura determinada. Normalmente, para esse objetivo, a hidrólise ácida é a mais viável, na qual se aplica dois estágios, a primeira com temperatura mais amena, chamada de pré-tratamento e outra, temperaturas mais altas, chamada de hidrólise efetiva (SILVA, 2010).

Um estudo detalhado acerca das vantagens e desvantagens na utilização de ácidos concentrados ou diluídos, apontam o concentrado com maior rendimento para este fim, no entanto, observando além de um bom rendimento, a diminuição com os gastos financeiros, os diluídos possuem bom rendimento, menos corrosivos e se adéquam a operações de larga escala devido a utilização de altas temperaturas (AGUIAR, 2017).

\subsection{Bioetanol}

$\mathrm{O}$ etanol ou álcool etílico $\left(\mathrm{C}_{2} \mathrm{H}_{6} \mathrm{OH}\right)$, é uma fonte energética promissora. Além disso, mesmo liberando uma grande quantidade de calor durante a sua queima, o etanol apresenta diferenças significativas em relação aos derivados do petróleo, como uma emissão maior de oxigênio, fonte mais limpa, maior desempenho em motores e um verdadeiro aditivo para gasolinas (SILVA, 2010). Por esses motivos, agregados a tentativa de diminuir o desperdício de alimentos no Brasil e no mundo, estuda-se a obtenção de etanol a partir desses resíduos. Neste caso, o desperdício gerado pelas vagens de feijão não reutilizadas serviria como uma nova fonte energética geradora chamada de bioetanol de segunda geração.

\section{METODOLOGIA}

O planejamento deste trabalho deu-se início com a colheita da vagem por meio de agricultores da região. Em seguida, a matéria-prima foi levada para o laboratório, onde a mesma foi secada em uma estufa com circulação forçada de ar, seguida do preparo do pó através de um liquidificador doméstico, tornando a matéria prima propícia para início do estudo, como visto na Figura 1, adiante. Para o pré-tratamento fez-se o uso do banho-maria (nova instruments), este equipamento evita que as soluções sejam expostas diretamente em contato com o fogo, fazendo-se o uso de temperaturas mais brandas, já na hidrólise ácida, utilizou-se a autoclave, aparelho que permite à substância um contato direto com o vapor de água em altas temperatura e pressão por determinado intervalo de tempo.

\subsection{Planejamento Fatorial}

Para a realização dos testes sobre a matéria prima, foi adotado um planejamento fatorial analisando quatro parâmetros: tipo de ácido (ácido sulfúrico $-\mathrm{H}_{2} \mathrm{SO}_{4}$ e ácido clorídrico $\mathrm{HCl}$ ), concentração do ácido, temperatura e tempo, conforme a Tabela 1. Na Tabela, é possível observar os quatro parâmetros em análise, com suas respectivas variações aplicadas as etapas de pré-tratamento e hidrólise ácida.

Tabela 1 - Parâmetros utilizados para o planejamento fatorial

\begin{tabular}{|c|c|c|c|c|c|}
\hline \multirow{2}{*}{ TESTE } & ÁCIDO & CONCENTRAÇÃO & TEMPO & TEMPERATURA \\
\cline { 2 - 6 } & 1 & $\mathrm{HCl}$ & $5 \%$ & $60 \mathrm{~min}$ & $90^{\circ} \mathrm{C}$ \\
\hline
\end{tabular}




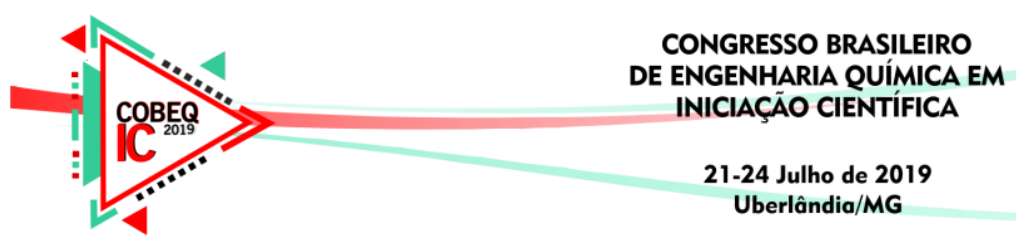

\begin{tabular}{|c|c|c|c|c|c|}
\hline \multirow{2}{*}{$\begin{array}{c}\text { PRÉ- } \\
\text { TRATAMENTO }\end{array}$} & 2 & $\mathrm{HCl}$ & $5 \%$ & $90 \mathrm{~min}$ & $90^{\circ} \mathrm{C}$ \\
\cline { 2 - 6 } & 3 & $\mathrm{HCl}$ & $0,05 \%$ & $90 \mathrm{~min}$ & $100^{\circ} \mathrm{C}$ \\
\cline { 2 - 6 } & 4 & $\mathrm{H}_{2} \mathrm{SO}$ & $5 \%$ & $60 \mathrm{~min}$ & $90^{\circ} \mathrm{C}$ \\
\hline \multirow{3}{*}{$\begin{array}{c}\text { HIDRÓLISE } \\
\text { ÁCIDA }\end{array}$} & 2 & $\mathrm{HCl}$ & $0,1 \%$ & $90 \mathrm{~min}$ & $125^{\circ} \mathrm{C}$ \\
\cline { 2 - 6 } & 3 & $\mathrm{HCl}$ & $0,1 \%$ & $90 \mathrm{~min}$ & $125^{\circ} \mathrm{C}$ \\
\cline { 2 - 6 } & 4 & $\mathrm{H}_{2} \mathrm{SO}_{4}$ & $0,1 \%$ & $120 \mathrm{~min}$ & $127^{\circ} \mathrm{C}$ \\
\cline { 2 - 6 } & & $0,05 \%$ & $90 \mathrm{~min}$ & $125^{\circ} \mathrm{C}$ \\
\hline
\end{tabular}

Após o preparo da biomassa, são adicionados em erlenmeyers a proporção de $1 \mathrm{~g}$ da amostra com $15 \mathrm{ml}$ do ácido diluído (pré-tratamento). Essa mistura é levada para banho-maria com variação de temperatura e tempo descrita na Tabela 1, em seguida, a mistura é filtrada e o licor é armazenado, lava-se o resíduo separado com água destilada e o destina para a etapa seguinte (hidrólise ácida). São obtidos novos licores e novamente guardados, Figura 2. Por último, os licores obtidos nos dois procedimentos descritos são destinados a leitura de absorbância pelo espectrofotómetro.

Figura 1 - Trituração da vagem.

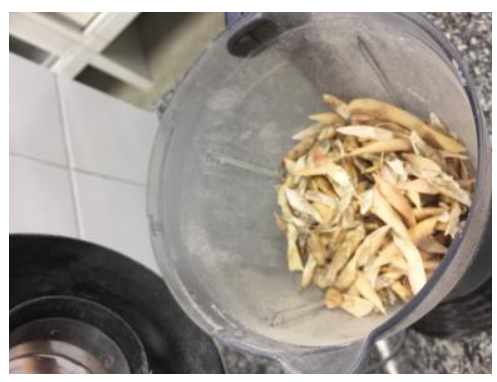

Figura 2 - Licores obtidos após aquecimento.

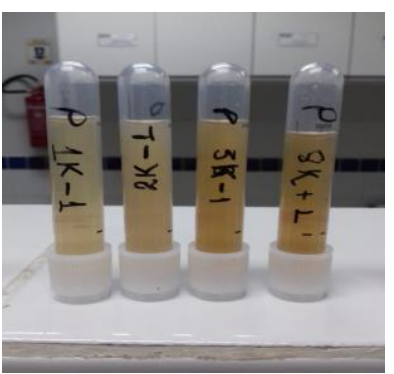

\subsection{Análise dos açúcares fermentescíveis totais (ART) por espectrofotometria}

Após a realização do pré-tratamento e da hidrólise, os licores obtidos foram destinados à análise de ART, Figura 3. Para isto, utiliza-se a técnica do DNS (ácido-3,5-dinitrosalicílico) descrito por Miller (1959) e, consecutivamente, é encaminhado para o espectrofotómetro, um aparelho capaz de mensurar a quantidade de radiação eletromagnética absorvida ou transmitida por uma determinada amostra e, neste caso, medindo os valores de absorbância das amostras em um comprimento de onda de 540mm, conforme visto na Figura 4.

Com isso, para um valor real da concentração de açúcares, utiliza-se a conversão da absorbância em ART, através da curva de calibração da glicose, obtida partindo-se do mesmo procedimento citado.

Figura 3 - Amostras com DNS.

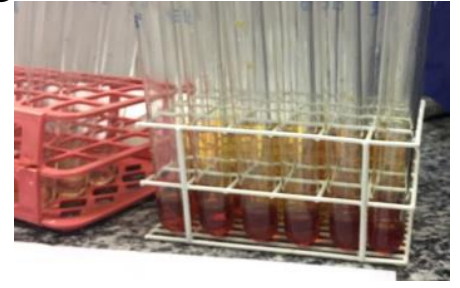

Figura 4 - Espectrofotómetro.

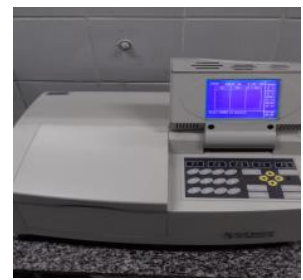




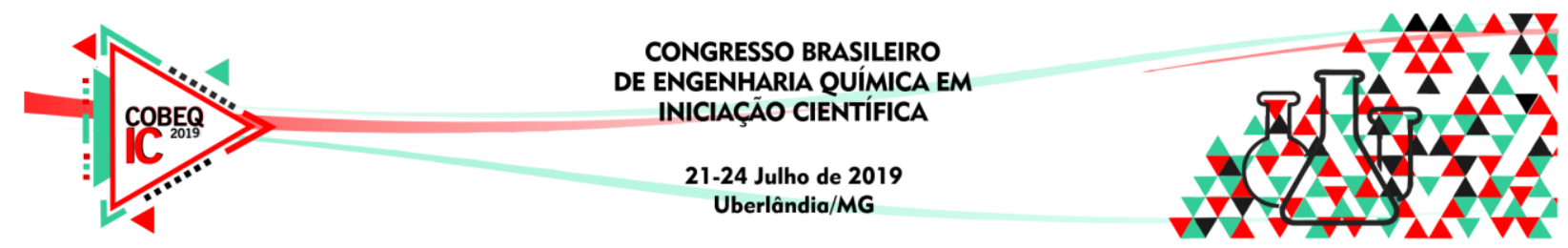

\section{RESULTADOS E DISCUSSÃO}

Com a aplicação das condições descritas na Tabela 1, obteve-se como principais resultados, esses visualizados na Tabela 2:

Tabela 2 - Concentração de ART

\begin{tabular}{|c|c|c|}
\hline \multirow{2}{*}{ TESTES } & \multicolumn{2}{|c|}{ CONCENTRAÇÃO (g/L) } \\
\cline { 2 - 3 } & PRÉ-TRATAMENTO & HIDRÓLISE \\
\hline 1 & 3,433 & 9,486 \\
\hline 2 & 4,106 & 8,479 \\
\hline 3 & 0,570 & 10,970 \\
\hline 4 & 3,775 & 8,712 \\
\hline AMOSTRA BRANCA & \multicolumn{2}{|c|}{0,335} \\
\hline
\end{tabular}

Além destes principais resultados apresentados, conforme Tabela 2, houve uma gama de outros 28 testes realizados. Porém, esses testes foram servindo como fontes preliminares para uma avaliação posterior de qual se sobressaia na maior quantidade em concentração de açúcares. Focando nos melhores rendimentos obtidos na produção dos açúcares, pode-se observar que há um elevado aumento entre o valor inicial (amostra Controle) de açúcar presente na matéria-prima com os obtidos por meio do tratamento com a pesquisa. Como pode ser visto, o $\mathrm{HCl}$ surte maiores efeitos que o $\mathrm{H}_{2} \mathrm{SO}_{4}$.

O êxito que estes resultados apresentaram só foi possível pela realização de um estudo detalhado sobre cada parâmetro analisado, avaliando assim, a influência da variação de cada um sobre a quantidade de açúcares produzidas. Após chegar numa concentração de ácido adequada, que produziu uma quantidade de açúcar significante, partiu-se para variação nos valores de temperatura e tempo. Podendo obter assim, nos últimos testes realizados, uma concentração de açúcares aproximadamente 18 vezes maior no pré-tratamento e de 33 vezes maior na hidrólise em relação a amostra Controle.

Apesar dos oito testes apresentados na Tabela 1 e 2 demonstrarem uma significativa quantidade de açúcares entres os dois ácidos utilizados, é observável uma superioridade do $\mathrm{HCl}$, isso apresenta uma contradição ao que foi visualizado na Literatura, no qual o outro ácido surtiria um maior efeito benéfico. Assim, é importante para estudos posteriores uma análise profunda dos dois tipos de ácido para esse objetivo. Ainda é importante visualizar que o terceiro teste, por exemplo, o qual possui maior quantidade de açúcares obtidos, apresenta a maior temperatura e tempo, uma concentração baixa no pré-tratamento e uma mais alta para hidrólise, confirmando assim o que foi interpretado no referencial teórico.

Ademais, é notório, em alguns casos, um relevante aumento da concentração de açúcares no pré-tratamento, enquanto que, quando é destinado para hidrólise, há uma perda desses valores. Tal circunstância é negativa para o processo, havendo uma degradação desses açúcares, comprometendo a sua fermentação. A situação pode ser interpretada por formação de inibidores durante os processos de aquecimento, os quais mesmo com os devidos cuidados, há uma grande probabilidade de adquirir. Entretanto, ainda se torna precoce a referida afirmação e é preciso medidas concretas para avaliação e uma possível validação.

\section{CONCLUSÕES}




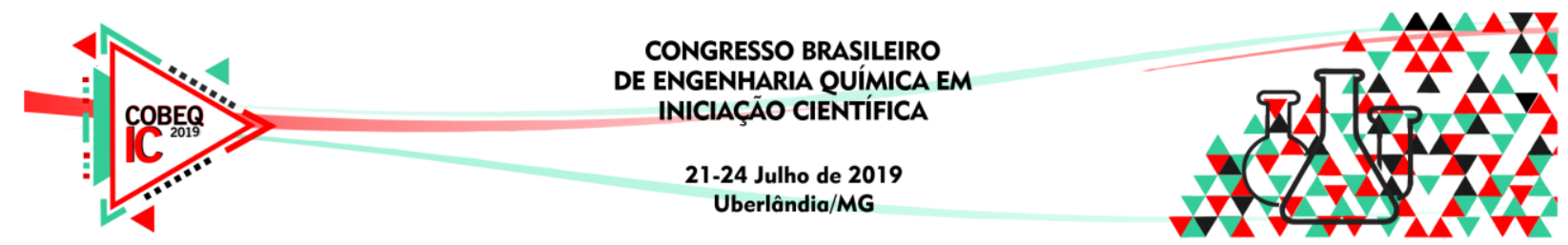

Até aqui, é possível identificar um melhor rendimento na hidrólise, sendo o último procedimento antes da fermentação com o ácido clorídrico $0,1 \%$, temperatura de $127^{\circ} \mathrm{C}$ e tempo de $120 \mathrm{~min}$, obtendo um aumento de 33 vezes mais açúcares em relação a amostra Controle. Portanto, é nítido a importância da concretização de um planejamento fatorial adequado, bem como a realização de testes aptos a evolução. A obtenção de resultados satisfatórios com a vagem de feijão quanto a produção de açúcares fermentescíveis é válido e abre oportunidade para a continuidade e melhoramento da pesquisa. Apesar de ocorrer algumas contradições com pesquisas realizadas na Literatura, os testes foram conseguindo um acréscimo gradativo na absorbância das amostras, o que permite um aumento significativo na concentração de açúcar, bem como obter boas referências para a prática das próximas etapas de fermentação e destilação.

\section{REFERÊNCIAS}

AgUiAR, H. R. R. de. Produção de Etanol de Segunda Geração. 2017. Monografia Graduação em Engenharia Química) - Curso de Graduação em Engenharia Química, Universidade Federal de Uberlândia, Minas Gerais.

CALIXTO, G. Q. Caracterização energética e avaliação dos produtos da pirólise rápida de resíduos agrícolas regionais. 2016. Monografia (Graduação em Engenharia Química) Departamento de Engenharia Química, Universidade Federal do Rio Grande do Norte, Natal

CHAGAS, Marcone César Mendonça das; LIMA, João Maria Pinheiro de; HOLANDA, José Simplício de. Feijão Macassar: do plantio a colheita. Natal, 2010.

IBGE. Maior produtor de feijão do país, 2017. Disponível em: $<$ https://agenciadenoticias.ibge.gov.br/agencia-noticias/2012-agencia-denoticias/noticias/18110-censo-agro-no-parana-a-busca-pela-realidade-rural-no-estadoque-mais-produz-feijao-no-pais.html>. Acesso em: 28 Abr. 2018.

RODRIGUES, C.; WOICIECHOWSKI, A. L.; LETTI, L. A. J.; KARP, S. G.; GOELZER, F. D.; SOBRAL, K. C. A.; CORAL, J. D.; CAMPIONI, T. S.; MACENO, M. A. C.; SOCCOL, C. R. Biotecnologia aplicada à agro \& indústria: Fundamentos e aplicações. São Paulo: Blucher, 2016. V. 4.

SILVA, N. L. C. Produção de bioetanol de segunda geração a partir de biomassa residual da indústria de celulose. 2010. Dissertação (Mestrado em Ciências) - Programa de pósgraduação em Tecnologia de Processos Químicos e Bioquímicos, Universidade Federal do Rio de Janeiro, Rio de Janeiro. 